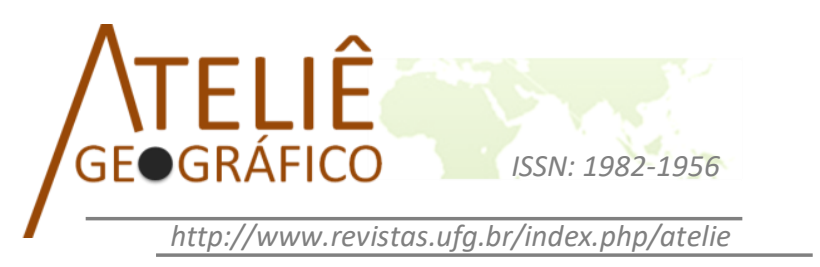

\title{
Planejamento e logística: as propostas de investimento da Confederação Nacional da Indústria e da Confederação Nacional do Transporte para o Rio Grande do Norte
}

\author{
Planning and logistics: the investment proposals of the National \\ Confederation of Industry and the National Confederation of \\ Transport for the Rio Grande do Norte, Brazil
}

\section{Planification et logistique: les propositions d'investissement de la Confédération nationale de l'industrie et de la Confédération nationale du transport pour le Rio Grande do Norte, Brésil}

Maxsuel de Moura Macedo

Universidade Federal do Rio Grande do Norte

maxsuelmmacedo@gmail.com

\begin{abstract}
Resumo
Este artigo tem como propósito analisar as propostas de investimento em transporte e logística da Confederação Nacional da Indústria (CNI) e da Confederação Nacional do Transporte (CNT) para o estado do Rio Grande do Norte. A análise será desenvolvida a partir de três propostas realizadas pelas confederações, a saber: o Projeto Nordeste Competitivo da CNI, o Plano CNT de Transporte e Logística e, Projetos Prioritários de Duplicação de Rodovias: Propostas de Solução, também de autoria da CNT.

Palavras-chave: fluidez territorial; planejamento; Confederação Nacional do Transporte; Confederação Nacional da Indústria; Rio Grande do Norte;
\end{abstract}

\footnotetext{
Abstract

This article has as purpose to analyze the investment proposals in transport and logistics of the National Confederation of Industry (CNI) and the National Confederation of Transport (CNT) for the Rio Grande do Norte state. The analysis will be developed from three proposals made by the confederations, to be specific: the Competitive Northeast Project (CNI), CNT Plan of Transport and Logistics and, Priority Projects of Highway Duplication: Proposed Solution (CNT).

Keywords: territorial fluidity; planning; National Confederation of Transport; National Confederation of Industry; Rio Grande do Norte.
} 


\begin{abstract}
Resumé
Cet article vise à analyser les propositions d'investissement pour le transport et la logistique de la Confédération nationale de l'industrie (CNI) et la Confédération nationale du transport $(\mathrm{CNT})$, de l'état du Rio Grande do Norte. L'analyse sera développée à partir de trois propositions faites par les confédérations, à savoir: le projet nord-est compétitif de la CNI, le Plan CNT des Transports et de la Logistique, les projets prioritaires de Duplication des Autoroutes: Solution proposée, également rédigés par CNT.

Mots-clés: fluidité territoriale; planification; Confédération nationale du transport; Confédération nationale de l'industrie; Rio Grande do Norte.
\end{abstract}

\title{
Introdução
}

O planejamento pode-se, em síntese, concebê-lo de um ponto de vista geográfico, como um norte para a ação racionalizada no território. As ações de planejamento para implantação de sistemas técnicos, com a finalidade de ampliar a fluidez, possuem intencionalidades que escapam a esfera do interesse público. Por isso, muitas vezes chega-se a conclusões que o atual planejamento estatal seria muito mais um planejamento corporativo.

As imbricações na elaboração do planejamento entre os setores público e privado constitui o cenário do complexo arranjo multifacetado da administração e do planejamento públicos. Por isso, é imprescindível analisar alguns desses agentes e suas propostas para o planejamento. No presente trabalho, focalizaremos as propostas da Confederação Nacional da Indústria (CNI) e da Confederação Nacional do Transporte (CNT) para transporte e logística, para tanto, buscaremos verificar quais ideologias e discursos sustentam tais projetos. À luz da teoria do espaço geográfico de Milton Santos, a análise enfocará, sobretudo, as propostas que tenham o Rio Grande do Norte como escopo, a saber: Projeto Nordeste Competitivo da CNI, Plano CNT de Transporte e Logística e, Projetos Prioritários de Duplicação de Rodovias: Propostas de Solução, também de autoria da CNT.

A crença disposta sobre as infraestruturas como sinergia para efeitos em cadeia, na qual culminaria no desenvolvimento de outros setores, reflete apenas a positividade do empreendimento, sobretudo para a economia, mas as consequências para a população e para o entorno são encaradas, muitas vezes, de forma secundária.

As propostas de investimento em grandes projetos de infraestrutura necessitam de uma justificativa coerente com a construção do futuro desejado pela população, pois, como propõe Carlos Matus (1996), o planejamento é um guia para ação, para criar o futuro que se almeja. A perspectiva apontada por Pedrão (2003) propõe que na análise dos projetos de infraestrutura se identifique as ligações existentes entre estes e os projetos sociopolíticos do país, só assim será possível identificar a real validade desses empreendimentos no âmbito nacional e regional.

Os grandes projetos de engenharia se não alinhavados com um projeto nacional coerente, concebido dentro de um planejamento arquitetado como um guia 
para o futuro, correm o risco de se tornarem um verdadeiro "cavalo de Tróia", nos avisa Milton Santos (2011), ampliando ainda mais as desigualdades regionais e alienando os lugares. Por isso se faz necessário analisar as propostas das associações corporativas, uma vez que são entidades de representação coletiva, com grande poder de ação e capacidade de se fazer valer sua vontade.

\section{Proposta da Confederação Nacional da Indústria: Projeto Nordeste Competitivo}

A Confederação Nacional da Indústria (CNI) é uma das entidades mais preocupadas com as condições infraestruturais no Brasil, pois estas implicam diretamente nas condições de circulação, visto que agrega os interesses de diversos setores industriais. Desta forma, constitui-se em uma situação lógica a busca por soluções que propiciem a redução com os custos logísticos para seus associados. Diante de tal fato, a CNI

resolveu investir em um Projeto de planejamento estratégico da infraestrutura de transporte de cargas da Região Nordeste, visando diminuir substancialmente o custo de transporte de cargas, racionalizando os investimentos e invertendo o posicionamento entre Governo Federal e a iniciativa privada (CNI, 2012, p.1).

A proposta da CNI, balizada pelo estudo da Macrologística Consultoria LTDA, propõe a inversão nos moldes do planejamento, eliminando o Estado da esfera do planejamento - volta-se a ideia de que o mercado, empresas e entidades a elas coligadas, podem organizar ou nortear o planejamento -, desta forma a responsabilidade passaria a esfera privada. Esse modelo tenta levar ao extremo o arquétipo neoliberal, nos moldes do planejamento estratégico corporativo, com isso, a função do setor público ficaria restrita às garantias de lucratividade de tais investimentos e os próprios recursos a serem utilizados, o que eliminaria grande parte dos riscos da imprevisibilidade do mercado. Nessa concepção o Estado é um obstáculo para a acumulação e circulação do capital, tese defendida com unhas e dentes pelos "teóricos" de um (neo)liberalismo mais rasteiro, refutada com extrema facilidade, uma vez que historicamente o Estado foi responsável por garantir a propriedade privada e o desenvolvimento exponencial das atividades econômicas. No modelo proposto pela CNI, a iniciativa privada passaria a propor a parceria ao Governo Federal, especialmente em projetos sem garantias de alta lucratividade a curto e médio prazos.

A justificativa utilizada para tal inversão é apresentada como a solução para a falta de sistematicidade dos projetos concebidos pelos ministérios e órgãos federais (porém, a maior parte dos projetos é concebida através de diálogos com a própria iniciativa privada), o que a iniciativa privada teria condições de realizar, pois seus projetos, além de possuírem sistematicidade e integração (formando eixos de transporte multimodal e integração regional), apresentariam menor custo e menor impacto ambiental e seriam sustentáveis. 
O estudo tem como objetivo elaborar um planejamento estratégico da infraestrutura de transporte e de logística de carga para os estado nordestinos, para tanto, visa:

- Integrar física e economicamente os estados envolvidos no estudo;

- Identificar e selecionar os Sistemas de Logística de menor custo, voltados para o mercado interno e externo, formados pela infraestrutura de transporte de cargas da região abrangida pelo estudo e torná-los mais competitivos;

- Complementar esses Sistemas de Logística com energia, telemática e capital humano de forma a transformá-los em Eixos Integrados de Desenvolvimento, e inserir a região abrangida pelo estudo na economia mundial;

- Liderar o processo de reconstrução e melhoria da infraestrutura brasileira, com a participação da iniciativa privada.

Nesse momento vale ressaltar a interessante proposição de superação dos eixos de transporte e sua transformação em Eixos Integrados de Desenvolvimento, com seu intermediário, sistema de logística. Pela lógica capitalista, ou melhor, lógica mecanicista, bastaria transformar os eixos de transporte em eixos de desenvolvimento para superar a antiga lógica dos estudos clássicos sobre transporte, baseados em "linhas vertebradoras" (ABLAS, 2003), isto é, os conhecidos corredores de exportação. Porém, esta carrega em seu seio o mesmo problema, não levar em conta a dimensão territorial, pensada como uma totalidade, como elemento dinâmico e vivo (SANTOS, 1994; 2008; 2000). A insignificância dada ao território no processo de desenvolvimento é acarretada pela "linearidade" da proposta, em que poucas são as dimensões analisadas, bastando um eixo de transporte, transformado em sistema logístico (terminais, EADIs, unidades de transbordo, veículos, impostos, fluxo de informação e eficiência gerencial), com o acréscimo de energia, telemática e capital humano, e obviamente baseado nas condições de competitividade, ou seja, bastaria aumentar a densidade técnica e informacional para que esteja completo o tão afamado desenvolvimento.

A metodologia do Projeto Nordeste Competitivo foi pautada, em primeiro lugar, na identificação das chamadas cadeias produtivas da Região Nordeste, não se restringindo às fronteiras estaduais, para tanto, foram coletados dados referentes à balança comercial de 2010. Depois da coleta foram selecionadas as principais cadeias produtivas em volume e as mais relevantes em termos de valor movimentado. Chegouse então ao número de 13 cadeias que representavam mais de $90 \%$ do volume total da produção movimentada para o ano base. Em um segundo momento analisou-se a produção agropecuária, extrativista e industrial, com isso, incluíram-se potenciais cadeias que não são relevantes na balança comercial regional, mas que são importantes no contexto nacional. Assim, foram identificadas 18 cadeias produtivas e 75 produtos. As cadeias selecionadas são as seguintes: açúcar e álcool, bebidas, cobre, madeira, petróleo e derivados, soja, adubos e fertilizantes, bovinos, ferro e aço, mandioca, 
químicos, trigo, alumínio, calcário e cimento, fruticultura, milho, sal, veículos e autopeças.

Além dessas cadeias, algumas outras também foram incorporadas (bentonita, cerâmica, gipsita, ilmenita e têxtil), mesmo sem possuírem grande representatividade em termos de valores, embora para a região tenham representatividade na geração de emprego e fluxos de carga.

Algumas dessas cadeias se fazem presente no Rio Grande do Norte, mesmo que de maneira incipiente ou sem significação dentro do contexto regional e nacional. Entre as de maior destaque estão: açúcar e álcool, bebidas, petróleo e derivados, calcário e cimento, fruticultura e sal, produção ceramista e têxtil.

$\mathrm{Na}$ fase seguinte, levantou-se a concentração da produção por município e sua distribuição geográfica, na qual resultou em 42 mesorregiões, com projeção para 2020. Para complementar as informações foram realizadas mais de 170 entrevistas, no Brasil e nos países vizinhos, com os responsáveis pelas cadeias produtivas, secretarias estaduais, ministérios, federações, associações produtivas, sindicatos de indústria e empresas.

A fase mais importante foi aquela em que se analisou o escoamento da produção, identificando por qual estado e porto são exportados ou importados estes produtos, e quais os principais países de origem e destino desses produtos. Ou seja, aqui nos interessam os fixos efluxos (SANTOS, 2012), e as dinâmicas derivadas.

No decorrer da análise focou-se também na localização do consumo de cada produto dentro do território nacional, com o objetivo de identificar os principais fluxos por produto e por mesorregião. A produção foi estimada para os próximos 10 anos, assim como o consumo e as exportações/importações, resultando em mais de 12 mil fluxos de produtos para a região Nordeste.

Para complementar essa fase foram levantadas as infraestruturas atuais de transporte de carga da região e dos países vizinhos, obtendo o resultado de 37 portos e terminais, 23 aeroportos, 34 principais rodovias, 4 ferrovias, 8 hidrovias, 4 dutovias, além de fixos para a armazenagem de graneis sólidos, líquidos e contêineres. Essa infraestrutura foi sobreposta aos fluxos gerados pelas cadeias produtivas, possibilitando, assim, verificar os gargalos logísticos nas rodovias, ferrovias, portos, dutovias, hidrovias e aeroportos. A partir da sobreposição realizada foram obtidos 58 Eixos Integrados de Transportes nacionais e internacionais eleitos de interesse da região Nordeste, a contemplar 196 obras, estimadas preliminarmente em de $\mathrm{R} \$ 71,1$ bilhões. Os investimentos seriam, em maior parte, destinados ao modal ferroviário $(48,1 \%)$, seguidos do modal portuário, $(22,9 \%)$, modal rodoviário $(21,6 \%)$ e apenas $6,8 \%$ para o modal hidrovário, e de $0,6 \%$ destinados para os aeroportos.

Em decorrência do valor e da magnitude dos investimentos considerados necessários até o ano 2020, o estudo privilegiou alguns eixos economicamente mais atraentes, e que levariam a redução nos custos com transporte e logística para as 
cadeias produtivas consideradas - custos de frete internos, custos de transbordo, tarifas portuárias e aeroportuárias, e de custos de frete marítimo para 6 tipos de cargas distintas: granéis minerais, granéis agrícolas, granéis líquidos, carga geral não paletizada, carga geral paletizada em contêineres ou caminhão baú e contêineres "reefers".

É interessante notar que o custo logístico da região Nordeste é apresentado como sendo da ordem de 6\% do PIB da região ( $\mathrm{R} \$ 30,2$ bilhões para o ano de 2010), ou seja, bem abaixo da média brasileira, que gira em torno de 11 a $12 \%$ do PIB, e inferiores aos valores apresentado para os Estados Unidos, 8\% do PIB. Não ignoramos o fato de que há uma enorme discrepância entre os PIBs brasileiro e norte-americano, além, é claro, das distintas características territoriais e da organização da matriz de transportes dos dois países e das particularidades internas ao território. Para justificar o incremento nos investimentos em novos sistemas de objetos destinados ao transporte, foram utilizadas progressões e ampliações dos fluxos com base em modelos matemáticos e softwares, tendo como cenário padrão o ano de 2020, mantendo-se a base material igual à atual e modificando a base dos fluxos, o que ocasiona o surgimento de gargalos pelo estrangulamento da capacidade da infraestrutura existente. Com o incremento dos fluxos para o panorama futuro, obtêm-se a ampliação dos custos logísticos totais da região, passando a aproximadamente $\mathrm{R} \$ 44,5$ bilhões.

Com a implantação da planilha de novas infraestruturas seria possível reduzir significativamente os custos logísticos, como é frisado pelo Projeto Nordeste Competitivo. Os principais impactos, de acordo com o Projeto, seriam:

- Redução de distância a ser percorrida gerando uma redução de frete (interno ou marítimo);

- Troca de um modal mais caro (ex: rodovia) por um mais barato (ex: hidrovia e ferrovia);

- Redução de frete interno por melhoria das condições do modal (ex: duplicação de uma rodovia pode gerar menor gasto com combustível e maior giro do caminhão, o que ocasiona redução do frete);

- Aumento da capacidade de movimentação, reduzindo gargalos em modais ou terminais que possuem menor custo logístico;

- Redução do número de transbordos.

O documento indica a necessidade da criação de um grupo multidisciplinar que teria a finalidade de elaborar e programar um plano de ação conjunta, para tornar viável em curto prazo à execução dos projetos, com cronograma e responsabilidades definidos. É sugerida a formação da equipe a partir de membros de ministérios, governos estaduais, bancadas legislativas estaduais e federais, organismos estaduais e federais, iniciativa privada envolvida, organizações não governamentais e universidades públicas e privadas. 
É interessante notar que o relatório inicia-se com a proposta de inversão do planejamento, passando a ser eminentemente elaborado pelo setor privado, e termina com a proposição da criação de uma força tarefa que abarca, em sua maioria, órgãos públicos para pôr em prática os interesses dos proponentes dos projetos.

\section{O Rio Grande do Norte no Projeto Nordeste Competitivo}

Agora vamos passar a analisar mais detalhadamente os projetos que englobam o Rio Grande do Norte. Pelo contexto deste trabalho, fica reduzido o espaço para tratarmos de maneira similar a região Nordeste e todos os eixos propostos pelo Projeto Nordeste Competitivo da CNI.

São quatro os projetos trajados sob o manto da prioridade que pertencem ao Rio Grande do Norte: a pavimentação da BR-110 entre Mossoró e Campo Grande, a construção do trecho da BR-110 entre Janduís e Serra Negra do Norte, dragagem para 12,5 metros no Porto de Natal e a construção do berço 04 do Porto de Natal. Exceto a construção do trecho da BR-110 entre Janduís e Serra Negra, os outros projetos já compõem o Programa de Aceleração do Crescimento (PAC), inclusive dois desses projetos já se encontram finalizados, enquanto a construção de um novo berço de atracação ainda não tem previsão para seu início.

Na descrição do projeto de construção da BR-110 entre Janduís e Serra Negra do Norte, trecho de $83 \mathrm{~km}$, não possui definições sobre a responsabilidade da construção. O resultado esperado para tal empreendimento é a melhoria do fluxo de passagem e o aumento de capacidade de captação no trecho; a construção visa acabar com a descontinuidade da BR-110, encurtando o trajeto, que de acordo com o estudo é realizado utilizando-se estradas estaduais (que geralmente apresentam péssimo estado de conservação, ou não se encontram asfaltadas). $O$ valor aproximado para o empreendimento é da ordem de R\$ 124,2 milhões, porém o estudo não apresenta uma proposição acerca da fonte de financiamento, se do PAC ou outra fonte, assim como não há nenhum estudo de viabilidade, Estudo de Impacto Ambiental (EIA-RIMA), projeto básico, ou seja, esse projeto por enquanto não passa de uma possibilidade. É importante frisar que a proposta segue o leito determinado originalmente para a rodovia, ou seja, o projeto não se constitui enquanto uma novidade, mas sim, a finalização do traçado já existente. Outro ponto a ser destacado é que o projeto da BR110 faz parte da integração do eixo rodoviário Mossoró/Salvador, que cruza a Paraíba e Pernambuco.

No caso da pavimentação da BR-110 entre Mossoró (entroncamento da BR304) e Campo Grande (entroncamento da BR-226), num trecho de $78 \mathrm{~km}$, a responsabilidade pela execução é do Departamento Nacional de Infraestrutura de Transportes (DNIT), uma vez que o projeto já estava assegurado pelo PAC2, este se constituindo como sua fonte de financiamento, não contando com a iniciativa privada. O empreendimento se encontra finalizado. 
Selecionamos algumas ações para o modal rodoviário, apesar de não fazerem parte dos eleitos como prioritários. Dentre estas está o projeto de duplicação da BR-101 (já finalizado) entre Natal e a divisa com a Paraíba, num total de $81 \mathrm{~km}$ de extensão. A obra estava sob a responsabilidade do DNIT, Exército e um consórcio, com financiamento ancorado no PAC1 e PAC2. Esse empreendimento visa o aumento da capacidade e melhoria do tráfego de cargas no Rio Grande do Norte e, além disso, deve ser ressaltado que possui dimensão maior do que foi apresentado no Projeto Nordeste Competitivo, pois a BR-101 tem origem no Rio Grande do Sul indo até o Rio Grande do Norte, margeando grande parte do litoral brasileiro. A rodovia se apresenta como uma rota turística e como conexão da Região Nordeste com o os estados do Sul e Sudeste, e de conectar a região ao Mercosul.

Outro projeto não prioritário para o modal rodoviário é a construção da BR226 entre a divisa do Ceará e do Rio Grande do Norte até o município de Patu. O trecho possui $69,7 \mathrm{~km}$ de extensão e pertence ao pacote de investimento do PAC1 e PAC2, sob a responsabilidade de execução do DNIT/DER-RN; hoje o empreendimento encontra-se finalizado. Esse projeto rodoviário tem como objetivo aumentar a capacidade e melhorar o tráfego de cargas no estado potiguar e de melhor conectá-lo ao Ceará.

Para o modal portuário há a proposta, já prevista no PAC e concluída, que concerne à dragagem e derrocamento de 10 para 12,5 metros de profundidade no Porto de Natal, que se constitui como um dos projetos prioritários mostrados anteriormente. Esta ação tem como finalidade aumentar a profundidade do canal do Porto e, por consequência, permitir o acesso de navios maiores, tipo Panamax ${ }^{1}$. Outro projeto para o porto, também previsto pelo PAC2, é a construção do berço 04 ao lado do berço 03, sob a responsabilidade da Secretaria Especial de Portos (SEP), com objetivo de ampliar a capacidade de recepção de carga e navios. Este projeto ainda não se encontra iniciado.

Para o modal aeroportuário, como previsto no PAC2 e já concluído, está a indicação de construção do Aeroporto de São Gonçalo do Amarante, que inicialmente contou com investimento público, mas que hoje está sob a responsabilidade do Consórcio Inframerica, que obteve sua concessão.

Um projeto interessante é a proposta de construção de um terminal rodoferroviário no município de Mossoró, com a finalidade de escoar a produção salineira oriunda do litoral setentrional. Esse projeto não se encontra entre os considerados prioritários no âmbito da Região Nordeste e, além disso, há a necessidade de revitalização das linhas ferroviárias estaduais para tal.

\footnotetext{
${ }^{1}$ Panamax corresponde a navios que possuem dimensões para passar nas eclusas do Canal do Panamá. São navios com comprimento de 965 pés $(294 \mathrm{~m})$, largura de 106 pés $(32,3 \mathrm{~m})$ e calado de 39,5 pés (12,04 m). São navios de porte médio.
} 
Para o modal ferroviário há uma proposta de revitalização do trecho da ferrovia Transnordestina entre Macau/RN e Itabaiana/PB, trecho de $525 \mathrm{~km}$, o projeto está calculado em torno de $\mathrm{R} \$ 1,3$ bilhão, valor estipulado através de projetos similares contidos no PAC. Por sua vez permitirá que a produção potiguar alcance, via ferrovia, os portos de Natal (RN), Cabedelo (PB) e Suape (PE). Espera-se com isso uma transformação da dinâmica nos estados envolvidos, sobretudo do Rio Grande do Norte, pois permitirá o barateamento do custo de circulação. Ademais, há o benefício de facilitar o transporte de peças e componentes das usinas eólicas que estão se instalando no Rio Grande do Norte, uma vez que o trajeto é realizado por meio do transporte rodoviário.

Complementando o projeto de construção do terminal rodoferroviário em Mossoró, há outro que compreende a construção de um ramal da Transnordestina Logística S/A (TLSA) entre Mossoró (RN) e Salgueiro (PE), trecho de 500 km, orçado em aproximadamente $\mathrm{R} \$ 1,5$ bilhão. Esse trecho integraria o Rio Grande do Norte à Ferrovia Nova Transnordestina, sendo Salgueiro um importante entroncamento no interior do Nordeste. A construção desse trecho possibilitaria a conexão entre o polo salineiro e os portos do Nordeste; desta forma, se ampliará as rotas de transporte para o sal marinho, assim como se integrará outros ramos industriais dinâmicos da região de Mossoró, como a produção e o processamento de frutas tropicais, extração de calcário, produção de cimento, de cerâmicas de revestimento. Vale ressaltar que o trajeto entre Mossoró e Sousa (PB) foi completamente destruído, tendo, inclusive, os trilhos retirados do leito da ferrovia.

Outro projeto destinado ao modal ferroviário é a construção do trecho ferroviário entre Quixadá (CE), Mossoró (RN) e Natal (RN), trecho de 540 km, orçado aproximadamente em $\mathrm{R} \$ 1,7$ bilhão, que pretende obter a ampliação da infraestrutura ferroviária do Nordeste, propiciando uma maior integração territorial na região, e de conectar a região de Mossoró e sua produção ao Porto de Natal e facilitar o acesso ferroviário ao Porto de Pecém (CE). Porém, como os demais projetos para o modal ferroviário não possui caráter prioritário, uma vez que estes apresentam alto custo de implantação e a estimativa de lucratividade é baixa, o que não justificaria do ponto de vista econômico a viabilidade dos investimentos para a iniciativa privada.

Em entrevista concedida ao jornal Tribuna do Norte ${ }^{2}$, Olivier Girard, sócio da Macrologística e coordenador do estudo encomendado pela CNI, afirma que não há viabilidade econômica para o investimento em ferrovias no Rio Grande do Norte. Isso se deve ao fato da distância entre os centros produtores e os portos serem curtas, menos de $500 \mathrm{~km}$, o que inviabiliza economicamente o grande investimento. Segundo ele, é "difícil sustentar economicamente uma ferrovia desse porte", pois "acaba limitando o

\footnotetext{
${ }^{2}$ MENDES, Adrielle. "Não há viabilidade para ferrovias no RN". Jornal Tribuna do Norte. 04 de novembro de 2012. Disponível em: <http://www.tribunadonorte.com.br/noticia/nao-ha-viabilidade-para-ferrovias-norn/235825>. Acesso: 04 de novembro de 2012.
} 
RN neste aspecto". E conclui: "fica mais muito mais prático movimentar carga de caminhão até um porto em outro estado do que fazer uma ferrovia". Essa justificativa é a mesma para a não inclusão do Rio Grande do Norte no trajeto da Ferrovia Nova Transnordestina, ficando a margem do principal investimento em ferrovia da Região Nordeste, uma vez que a distância física entre Mossoró e Fortaleza (portos de Pecém e Fortaleza) é pequena, o que não justificaria a construção de uma ligação ferroviária.

Com isso, todas as propostas de construção ou revitalização da malha ferroviária do Rio Grande do Norte foram excluídas ou postas como secundárias e inviáveis economicamente. Deve-se observar que o período para retorno do investimento esperado é para o curto e médio prazo, o que interfere diretamente na viabilidade do investimento para o setor privado.

É importante trazer à luz a divergência entre a Federação das Indústrias do Estado do Rio Grande do Norte (FIERN) e a CNI no que concerne o Projeto Nordeste Competitivo. Em entrevista, Amaro Sales, presidente da FIERN, concedida ao jornal Tribuna do Norte, diz que o estudo realizado pelo Macrologística Consultoria é insuficiente e com curta visão. Para ele o estudo é deficiente por considerar

\begin{abstract}
Puramente a questão de política geoeconômica, ou seja, de logística de resultado, de logística de movimentação de cargas, não se trabalhou por amostragem ou hipótese. Feito sem considerar as questões de ordem geopolítica que, geralmente, ocorre nas obras de infraestrutura em um país de dimensões continentais e desigualdades regionais ${ }^{3}$.
\end{abstract}

No tocante ao estudo da Macrologística que indicou como inviáveis os investimentos em ferrovias, o presidente da FIERN mostra-se contrário a tal argumento - a viabilidade de uma ferrovia só é possível se a distância entre os pontos for superior a $500 \mathrm{~km}$-, que é para ele puramente técnico. "O que deve pesar é se há carga, se houver compensa, se tiver os ramais necessários para as interligações, compensa" ${ }^{4}$. Para a FIERN, um ramal entre Natal-Mossoró, com 420 km seria viável, uma vez que há o Aeroporto Internacional de São Gonçalo do Amarante, os polos industriais de Mossoró, as fábricas de cimento, cerâmica, além da Zona de Processamento de Exportações (ZPE) de Macaíba, que dessa forma viabilizariam a ferrovia pela quantidade de carga produzida, servindo como ancora para atração de novos investimentos. Importante frisar que a ZPE de Macaíba ainda não se encontra em operação.

A estruturação de corredores de fluidez pode de um lado favorecer $o$ desempenho das empresas que exportam, e as que abastecem o mercado interno; do mesmo modo, pode levar à desestruturação territorial, uma vez que são priorizados alguns subespaços, que se tornam pontos luminosos (eixos luminosos).

\footnotetext{
${ }^{3}$ TRIBUNA DO NORTE. “A Fiern defende um novo Porto". Jornal Tribuna do Norte. Natal, 11 de Novembro de 2012. Disponível em: <http://www.tribunadonorte.com.br/noticia/a-fiern-defende-um-novoporto/236338>. Acesso: 11 de novembro de 2012.

4 idem.
} 
Para Castillo e Frederico (2010) existe um embate entre duas lógicas: uma lógica das redes e uma dos territórios. A primeira resulta em ilhas de eficiência produtiva, adestradas aos imperativos hegemônicos, de qualidade e custos, baseados em critérios internacionais, assim como em corredores de fluidez material; do outro lado, vastos espaços viscosos que são cruzados justamente pela lógica das redes, nos quais imperam a mobilidade precária ou mesmo inexistente.

\section{Propostas da Confederação Nacional do Transporte para investimento em transporte e logística}

A Confederação Nacional do Transporte (CNT) lançou em 2011 o Plano CNT de Transporte e Logística, que tem como objetivo "identificar as intervenções necessárias para o melhor desempenho e integração dos sistemas de transporte do país" (CNT, 2011, p.11). A metodologia parte inicialmente da divisão em dois grandes grupos: os projetos de integração nacional e os projetos urbanos. Enquanto o primeiro é pautado em eixos de transporte, o segundo é baseado nas regiões metropolitanas.

Os projetos de integração nacional estão estruturados com base em eixos de transporte, constituídos por um conjunto de infraestruturas atreladas à produção econômica e distribuição de bens para centros consumidores e a pontos de exportação. Os eixos são formados por eixos estruturantes e por ligações complementares ao eixo estruturante. Foram estabelecidos nove eixos estruturantes, a saber: 1) Eixo NordesteSul; 2) Eixo Litorâneo; 3) Eixo Norte-Sul; 4) Eixo Amazônico; 5) Eixo Centro-Norte; 6) Eixo Norte-Sudeste; 7) Eixo Leste-Oeste; 8) Eixo Nordeste-Sudeste e; 9) Eixo de Cabotagem.

Para contemplar o objetivo da CNT foram elencados alguns projetos necessários para a integração nacional; o território aqui é amplamente entendido como palco para a fluidez econômica, um verdadeiro substrato físico onde se alocam as infraestruturas. A seleção dos projetos foi estabelecida através de coleta em entidades afiliadas à CNT que atendem aos interesses dos operadores de transporte das regiões brasileiras, levou-se também em consideração as pesquisas já realizadas por outras entidades, como a Confederação Nacional da Indústria (CNI), a Confederação da Agricultura e Pecuária do Brasil (CNA), a Companhia Nacional de Abastecimento (Conab), a Iniciativa para a Integração da Infraestrutura Regional Sul-Americana (IIRSA) e órgãos governamentais e não governamentais ligados ao setor de transporte e logística. Os projetos apresentados pelo plano não incorporaram os projetos selecionados pelo PAC, uma vez que possuem recursos garantidos via investimento estatal.

Os projetos selecionados obedecem a seguinte lógica, como apresentada no plano: os possíveis investimentos foram alocados nos eixos principais, ou seja, nos corredores de fluxo de carga efetiva e/ou potencial entre as regiões brasileiras, ligando, assim, os pontos de atração e geração de fluxos como portos, postos de fronteira, 
capitais estaduais e as áreas de produção agrícola e industrial, entre outros. Foram selecionados os pontos já luminosos do território para receber ainda mais infraestrutura, ou seja, busca-se a partir da concentração infraestrutural a ampliação das relações econômicas, e, por conseguinte, ampliar a circulação do capital. Essa forma de planejamento é obviamente adotada para aceleração das relações econômicas, uma vez que a concentração de capital fixo e circulante intensifica a produção, reduz os custos de circulação e distribuição, aproxima a produção dos centros consumidores, sobretudo as grandes e médias cidades (apesar de sabermos que hoje, com o advento de meios cada vez mais velozes e com a logística, não seja tão significante a distância física).

Vale salientar a importância e a continuidade do discurso construído em torno dos eixos de transporte, com ligações a pontos de escoamento e exportação. Por outro lado, há uma preocupação com os centros consumidores, as grandes cidades, que para um país com grandes dimensões territoriais como o Brasil é uma necessidade premente. Ressaltamos também que o pensamento linear estabelecido pelos eixos não permite estabelecer conexões com a rede urbana, constituída por cidades com distintas características, tamanhos e dinâmicas. Ao que parece, são distintas as epistemologias que comportam o estudo da rede urbana e a que engloba os "eixos", uma vez que pensar a rede urbana necessita-se pensar a região e a vida de relações que a constitui; compreender não apenas as verticalidades, como também as horizontalidades (SANTOS, 2008).

Retomando, o plano, como fica explícito em seu título, é permeado pelo discurso da logística, porquanto permite maior agilidade para a circulação do capital, sendo apresentada como o meio pelo qual o custo de transporte será amortecido, reduzindo, consequentemente, os custos das empresas. Por outro lado, apresenta como fator fundamental para a logística - compreendida aqui como um processo de planejamento, operação e controle de fluxo - a oferta de infraestrutura viária, de veículos e terminais.

É de suma importância notar que o Rio Grande do Norte, foco da nossa análise, não comporta nenhum dos eixos estruturantes baseados em infraestruturas rodoviária ou ferroviária - fato semelhante apenas a Roraima, que por sinal está completamente fora de qualquer iniciativa de integração territorial -, cabendo apenas à integração no Eixo Cabotagem, que se integra ao Porto de Natal e ao Terminal Salineiro de Areia Branca, já que esse eixo circunda toda a costa brasileira, conectando os principais portos do país.

O Plano CNT de Transporte e Logística propõe para o Rio Grande do Norte investimentos em aeroportos, ferrovias, portos e rodovias, além de intervenções em infraestruturas urbanas. São destacados alguns projetos de maior impacto no que corresponde à integração nacional, entre eles a construção de $243 \mathrm{~km}$ de ferrovias, ampliação da área portuária do Porto de Natal, assim como a duplicação de $308 \mathrm{~km}$ de rodovias e da recuperação de $282 \mathrm{~km}$ de pavimentos. Já está inclusa a ampliação do 
terminal de cargas do Aeroporto Internacional de São Gonçalo do Amarante (o que acarreta em uma perspectiva otimista do uso efetivo da área já planejada).

A proposta da CNT para investimentos no Rio Grande do Norte foca na recuperação e ampliação da malha infraestrutural existente; busca-se a adequação às necessidades geradas a partir do incremento dos fluxos reais ou da possibilidade de acréscimo futuro, vislumbrado pelo cenário econômico, sobretudo pelas potencialidades ofertadas pela fruticultura irrigada e pelo extrativismo mineral.

A proposta segue algumas recomendações já realizadas por outros planos, como a necessidade do aumento do calado do Porto de Natal através de dragagem, possibilitando assim a atracação de embarcações maiores. Essa ação já está inserida nas ações do PAC, inclusive a ação já está concluída.

Em relação ao Terminal Salineiro de Areia Branca é reconhecida sua grande capacidade de movimentação de sal marinho, no qual é especializado, por isso o estudo propõe a ampliação de sua área portuária com o objetivo de aumentar a capacidade de processamento de carga. Ação já realizada no âmbito do PAC.

O transporte rodoviário é apontado como a principal forma de escoamento e circulação no estado, portanto exige uma atenção especial nas condições de manutenção e adequação das rodovias. No entanto, deve ser sublinhado que o plano não discorre sobre as rodovias estaduais, pois foca apenas às rodovias federais por se tratar de um conjunto de propostas de intervenção para o governo federal. É sugerida no plano a duplicação do trecho da BR-304 entre Mossoró e Macaíba - proposta amplamente sugerida em outros planos, por isso incluída no PAC2 e atualmente está com as obras em andamento em um trecho - graças ao crescimento do fluxo, como também do desenvolvimento econômico da região. Outro fator de impacto é o acréscimo do fluxo em alguns meses, mormente o transporte de frutas em direção ao Porto de Natal.

No que concerne ao modal ferroviário é destacada a extensão da malha estadual, com $364 \mathrm{~km}$, - a operação das linhas era de responsabilidade da Transnordestina Logística S.A. que acabou não sendo efetivada, embora praticamente desativada e sem condições de uso. Por consequência da produção mineral e agropecuária é aventada a possibilidade de construção de novo trecho entre os municípios de Mossoró e Alexandria, com a intenção de se conectar a Sousa, na Paraíba, criando, uma conexão regional. Essa integração regional é benéfica não apenas para o grande capital, é de suma importância para a dinamização do mercado regional, sendo este integrado somente por rodovias, e de trazer nova opção, o próprio modal ferroviário, o que pode trazer uma sobrevida para as regiões interioranas do Rio Grande do Norte e da Paraíba. No entanto, esses projetos, observados conjunturalmente numa perspectiva temporal de curto e médio prazo não pareçam ser viáveis. 


\section{Projetos Prioritários de Duplicação de Rodovias: Propostas de Solução}

Outro estudo da CNT, denominado Projetos Prioritários de Duplicação de Rodovias: Propostas de Solução, sendo constituído de pré-projetos de análise de viabilidade de duplicação de rodovias, visa apresentar soluções viáveis aos gargalos infraestruturais das rodovias brasileiras por meio de Parcerias Público-Privadas (PPP's). A proposta qualifica como "estratégico e emergencal" o conjunto de obras de infraestrutura previsto no estudo, o que tornaria necessário o enquadramento no Regime Diferenciado de Contratações Públicas (DRC), que dentre as especificidades instituídas por $1 \mathrm{ei}^{5}$, deveria ser ampliado para contemplar as obras de infraestrutura de transporte, embora esteja prevista sua utilização em ações promovidas pelo PAC. Outro detalhe previsto na proposta da CNT para garantir a viabilidade econômico-financeira é a cobrança de pedágio a cada $50 \mathrm{~km}$ que for duplicado.

Para a manutenção da tarifa a preços "acessíveis" o projeto indica a necessidade da criação de um fundo de investimento, composto por recursos da Cide ${ }^{6}$. Segundo o relatório

o objetivo é viabilizar a contrapartida de recursos do governo em préprojetos de PPP como alternativa à execução orçamentária tradicionalmente utilizada. Pela proposta apresentada, seriam destinados aproximadamente $35 \%$ por ano da arrecadação bruta da Cide para esse fundo, o que poderia dar segurança e atratividade aos investimentos privados, além de garantir uma tarifa máxima de $\mathrm{R} \$ 3,00$ por praça de pedágio (CNT, 2012, p.7).

A seleção dos pré-projetos obedeceu a critérios que incluem a importância para o desenvolvimento econômico, para a integração regional e os benefícios para a população, através do ganho de segurança viária e do aumento de desempenho operacional. Os pré-projetos foram divididos em dois grandes grupos, sendo que o primeiro agrupa as rodovias que apresentam grande quantidade de fluxos de veículos e densidade de tráfego elevadas, o que justificaria economicamente o investimento, não necessitando assim da contrapartida estatal. $O$ segundo reuniu as rodovias que apresentam importância para a integração nacional e regional, entretanto possuem volume de tráfego insuficiente para justificar em âmbito econômico-financeiro os investimentos necessários. De tal modo, necessitariam de complementação financeira do governo para garantir a modicidade da tarifa a ser empregada.

Diante do escopo do trabalho restringiremos a análise apenas ao que for de interesse direto para o Rio Grande do Norte. A BR-304, trecho entre Mossoró e Macaíba, numa extensão total de $242 \mathrm{~km}$, composta por pista simples, é apresentada no estudo como uma rodovia de interesse à integração regional, isto é, uma rodovia que possui tráfego diário médio. A proposta apresentada indica que a rodovia deve ser entregue à iniciativa privada, que seria responsável pela duplicação total do trecho e de

\footnotetext{
${ }^{5}$ http://www.planalto.gov.br/ccivil_03/_ato2011-2014/2011/Lei/L12462.htm.

${ }^{6} \mathrm{http} / / / \mathrm{www}$. receita.fazenda.gov.br/Legislacao/Leis/2001/lei10336.htm.
} 
sua manutenção, tendo como contrapartida a cobraça de pedágio a cada $50 \mathrm{~km}$ duplicados, além de complementação financeira estatal (CNT, 2012).

A análise da viabilidade econômica para o empreendimento foi indicada através de simulação do investimento e do provável retorno; o período de concessão previsto seria de 25 anos; a rodovia apresenta um volume médio diário de 4.332 veículos, com taxa de crescimento prevista durante o período de concessão de $2 \%$ ao ano. Nos $242 \mathrm{~km}$ que seriam duplicados, obedecendo ao cálculo de uma praça de pedágio a cada $50 \mathrm{~km}$, foram previstas quatro praças de pedágio, com uma distância média de $60,5 \mathrm{~km}$. O custo anual de operação (manutenção) é da ordem de R $\$ 16$ milhões, valor a ser assumido pela iniciativa privada durante o período de concessão. A proposta (simulação) para a duplicação é orçada em mais de $\mathrm{R} \$ 1,1$ bilhão, provenientes da iniciativa privada, com valor de manutenção total de aproximadamente de $\mathrm{R} \$ 400$ milhões. A complementação financeira por meio da Cide é indicada num valor total para $\mathrm{R} \$ 2,3$ bilhões; o valar da tarifa de cada praça de pedágio seria de $\mathrm{R} \$$ 3,00. Assim, o empreendimento dentro da simulação realizada oferece uma Taxa Interna de Retorno (TIR) de 8,14\%, o que justificaria economicamente tal empreendimento.

Esta proposta é mais uma entre tantas que concebe o território enquanto fundo de reserva para o lucro. A concepção de que a duplicação e manutenção das vias sejam realizadas pela iniciativa privada e que a cada $50 \mathrm{~km}$ de rodovia duplicada sejam instaladas praças de pedágio ambiguamente cria de um lado fluidez e de outro, viscosidade (SANTOS; SILVEIRA, 2011); uma das necessidades do período é tornar ágil a circulação de pessoas, mercadorias, dinheiro, informações, etc; uma das formas de alavancar a fluidez é através de melhorias dos sistemas de engenharia, que por sua vez aperfeiçoam o movimento. Isso é buscado dentro da proposta da CNT, mas a criação de pedágios em pequenas distâncias em um território marcadamente pobre e desigual, numa rodovia de grande importância para a circulação de pessoas, tornará o movimento ainda mais raro, criando-se uma espécie de viscosidade imposta, não em razão das péssimas condições de conservação, mas pelo alto custo para se trafegar. Obedecendo a projeção do estudo da CNT, a movimentação entre as cidades de Mossoró e Natal pagar-se-á o valor referente a quatro praças de pedágio, afora os demais custos com transporte. Ou seja, cria-se uma nova forma de imobilidade, atrelada a lógica puramente econômica; constroem-se equipamentos modernos que permitem maior velocidade e segurança, concomitantemente se limitam o uso àqueles que podem arcar com os custos para usufruí-los. Se não estivéssemos falando de um bem público, uma rodovia federal, pareceria um discurso vazio, mas se trata de uma infraestrutura de transporte que é responsável por parte significativa dos fluxos de pessoas e cargas no estado, conexão entre a capital potiguar e a capital cearense. Ademais, é responsável por absorver o fluxo de diversos municípios que buscam serviços mais complexos nas duas maiores cidades do estado, Natal e Mossoró (figura 
1), como bem mostra o estudo Região de Influência das Cidades (Regic), baseando nos centros gestão do território (CORRÊA, 1996).

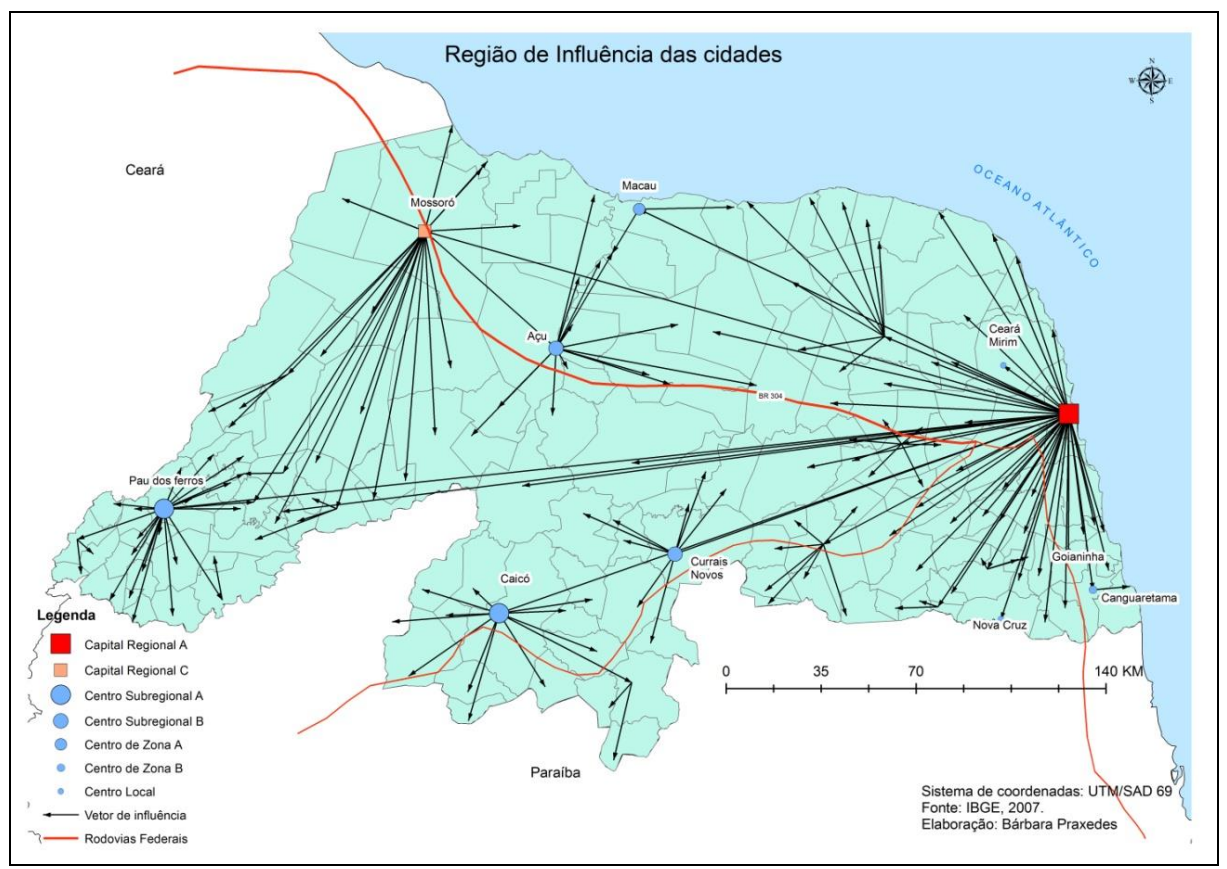

Figura 1 - Rede urbana do Rio Grande do Norte

Essa proposta do ponto de vista econômico é atraente para as empresas que se interessarem pela concessão - apesar de que atualmente alguns trechos não estejam despertando o interesse dos grupos privados em obtê-las por não acharem a viabilidade e o lucro satisfatório em curto em médio prazo -, pois a rodovia liga as duas maiores cidades do estado, onde flui grande parte da riqueza produzida.

Contudo, esse projeto do ponto de vista social é uma aberração, porque imobilizaria milhares de pessoas por não terem condições de arcar com os custos dos pedágios, além do significativo aumento que teria na composição do preço das passagens intermunicipais, que por sinal são caras em comparação a qualidade do serviço prestado. Outro problema seria o aumento do preço do frete, o que acarretaria no aumento dos preços dos produtos.

Outro fator que devemos destacar será a possível fragmentação do território estadual, tendo em vista que o projeto indica quatro postos de pedágio, e assim tornaria os fluxos mais escassos entre as regiões Oeste (onde se encontram Mossoró e Pau dos Ferros) com a região Leste, onde se encontra a Região Metropolitana de Natal (RMN). 
Como se pode ver, o espaço banal concebido por Santos (2008) não é levado em consideração, sobretudo, quando a lógica capitalista (HARVEY, 2011) é quem ordena tal empreendimento. O território tem voz, e as ações que emanam do povo se mostram com força contra os empreendimentos que visam apenas o lucro, excluindo milhares de pessoas dos seus direitos de cidadão e do seu direito ao entorno e suas relações.

Esse exemplo é um espelho para enxergamos a violência diária, a violência do dinheiro (SANTOS, 2008), a que estamos submetidos. A lógica capitalista não pode ser a preponderante, o "custo econômico" não pode ser o primeiro item da análise de um projeto de investimento em nível macro, no qual milhares de pessoas estão envolvidas. A análise deveria, em primeiro lugar, levar em consideração o território e as relações firmadas dentro desse arranjo, isto é, considerar o real "custo social" de tais ações, e pelo que podemos vislumbrar é preocupante. Seus efeitos podem desarticular ainda mais a frágil base econômica do Rio Grande do Norte, e de provocar diversas modificações nas relações entre cidades, nos fluxos materiais e na própria rede urbana.

Dentro do que fora planejado pela Confederação Nacional do Transporte, o governo federal, em diálogo com o governo estadual, decidiu incluir parte da duplicação da BR-304, trecho entre o município de Macaíba e o entroncamento com a BR-226, denominado popularmente de Reta Tabajara. A duplicação faz parte das ações do PAC2, que atualmente se encontram em andamento. A duplicação completa da rodovia está prevista, embora ainda esteja nas fases preparatórias, sem previsão para o início das obras?

\section{Considerações finais}

Como bem assinalou Ribeiro (2003) o território é o traço de união entre o passado e o futuro imediato, é a mediação entre o que foi e o que pode vir a ser, mas o território é sempre a configuração presente, mesmo que suas formas e objetos sejam herdados do passado. Essa condição de mediação entre as formas de existência pretéritas e atuais e o devir histórico põe o território como elemento central e estrutural no desenvolvimento do planejamento, portanto é imprescindível levá-lo em consideração na elaboração dos planos e projetos, com o risco de torná-los estéreis e ineficazes, intensificando ainda mais o seu caráter pontual, setorial e fragmentador.

Esse casamento entre o território e o devir histórico é alicerçado pelas práticas políticas - política concebida em sua ampla acepção -, são elas que levam o presente ao futuro. Para Ribeiro (2003) é através do projeto que se efetiva essa passagem entre o presente e o futuro, através da potência da práxis, que

7 COMITÊ GESTOR DO PAC. $10^{\circ}$ Balanço, março/junho de 2014. Disponível em: <http://www.pac.gov.br/pub/up/relatorio/19e58f2b7b43729be07ca7b500d30197.pdf〉. Acesso em: 21 de janeiro de 2016. 
inscreve desígnio em condições herdadas e cria desígnios, condições objetivas e subjetivas que estão para além da finalidade que imediatamente conduziu a ação transformadora em materialidade. Existem relações previstas e imprevisíveis entre objeto e ação, o que constitui a condição do acontecimento, compreendido como existência e projeto" (RIBEIRO, 2003, p.32).

Portanto, é “o projeto, que é portador da força necessária à superação potencial da reificação e da alienação, exige a compreensão dos sentidos da ação e, assim, da própria existência" (RIBEIRO, 2003, p.32). O território implica diretamente em uma teoria da ação, de uma ação política, eficaz, que se diferencie das práticas e concepções de uma "individualidade isolada", como assinala Mészáros (2009).

O planejamento não pode ser um dado técnico, estritamente; deve ser concebido enquanto campo para a ação política, sobretudo se o território for o elemento norteador a superar as perspectivas parciais, compostas por uma epistemologia fragmentadora que toma a realidade enquanto conjuntos organizados, cada qual em sua determinada caixa, espaço-temporalmente seccionadas. Esta perspectiva nos leva a conceber a realidade abstratamente, impossibilitando-nos de alcançar uma visão mais totalizante da própria realidade.

O plano não pode ser uma camisa de força, conquanto não necessite ser baseado em formulações gerais e abstratas, sem um substrato concreto. Deve, ao contrário, ser ancorado nas bases territoriais, aquilo que Milton Santos chamou de território como norma (2008).

O planejamento, como foi mostrado ao longo deste artigo, é tido como uma ferramenta a serviço de preceitos econômicos no mínimo duvidosos do ponto de vista da totalidade societária, e em relação à sua concepção de território - meramente um substrato material com limites jurisdicionais. Afora apresentarem, como no caso da CNI, uma proposta descabida de inversão da elaboração do planejamento, passando a ser um instrumento do setor privado, a impor sua lógica a todo o território.

No conjunto de ferrovias indicadas pelo Projeto Nordeste Competitivo, predomina o pensamento clássico dos corredores de exportação; uma ferrovia a integrar-se a um porto, e não como elemento a ampliar a integração territorial e regional que possibilitaria a criação de uma densa malha ferroviária, conectando todo o território nacional num verdadeiro sistema de transporte, pensado e estruturado de forma ampla, e em múltiplas escalas. Devemos sair desse pensamento linear, dos eixos de transporte designados à exportação, para pensarmos em outros termos territoriais, e assim criar novas possibilidades e novos modelos de desenvolvimento.

Os eixos de transporte (eixos integrados de desenvolvimento, como na proposta da CNI) são fruto do pensamento único (SANTOS, 2008), alicerçado no mito do progresso (DUPAS, 2006), na linearidade, não passando de um arquétipo lógicoformal firmado mais na dedução e na intuição analítica do que propriamente baseados em dados concretos, na realidade objetiva. Essa lógica da economia, mecanicamente fundada, inverte as determinações materiais (MÉSZÁROS, 2009), subvertendo-as em 
determinações abstratas e abstratamente concebidas. Quando se fala em desenvolvimento, não se pode concebê-lo de forma parcial, uma vez que somente os eixos mais competitivos se tornariam desenvolvidos, ou seja, essa noção de desenvolvimento já parte da premissa de manter o desenvolvimento geográfico desigual em termos aprofundados (HARVEY, 2013). A racionalidade da técnica que redundaria no progressivo desenvolvimento não passa de pura fé, crença mística no progresso da razão. A luz que caminha sempre para o infinito, parte essencial no desenvolvimento dos povos, espécie de dogma da evolução.

Por isso que projetos concebidos em âmbito regional são importantes, pois, além de integrar fisicamente o território, ampliam-se os fluxos não só de cargas, mas de pessoas, informações etc., assim como possuem a capacidade de romper com o modelo rodoviarista imperante na região e no país como um todo. No entanto, grande parte desses projetos apenas focaliza o transporte de cargas, pois o transporte de pessoas fica em segundo plano, marginalizado (fato compreensível quando o objetivo é a análise da competitividade, como no caso do Projeto Nordeste Competitivo da CNI).

Do ponto de vista da logística territorial, o estudo da CNT (Plano CNT de Transporte e Logística 2011) tem no seu cerne propostas que buscam o adensamento de pontos já densos ou que já possuem uma maior dinâmica em relação ao contexto local e regional, o que nos faz vislumbrar no tempo a incapacidade de transformações significativas na dinâmica territorial, derivando no máximo em alargamentos dos fluxos e o engessamento das estruturas sociais e territoriais.

Portanto, como foi apresentado, o Plano CNT de Transporte e Logística 2011 é mais um entre tantos a destacar a importância do investimento em infraestruturas de transporte e logística, que por sua vez implicariam diretamente nas condições de desenvolvimento econômico do país. São nesses argumentos de afirmação que submergem as reais intencionalidades do plano, de aceleração da acumulação capitalista, afora, é claro, a transferência para o setor público dos investimentos que requerem maior aporte financeiro e capacidade de ação.

No outro estudo elaborado pela CNT - Projetos Prioritários de Duplicação de Rodovias: Propostas de Soluções - fica nítida a falta de comprometimento com a realidade, uma vez que indica como solução a duplicação de diversas rodovias brasileiras a serem realizadas pela iniciativa privada, tendo como contrapartida a instalação de praças de pedágio a cada $50 \mathrm{~km}$. Esse projeto propende a ampliar ainda mais as desigualdades espaciais, assim como criar uma espécie de viscosidade imposta.

Como bem nos lembra Vainer (2007), em um projeto nacional o projeto territorial deve ocupar um papel central, porquanto a privatização de setores estratégicos, como as infraestruturas, historicamente acabou tendo como corolário a privatização dos processos de planejamento e controle territorial, intrinsecamente ligados aos grandes projetos de investimentos. 
As próteses territoriais, esses grandes objetos que o homem dispõe no espaço geográfico, ou melhor, que o constitui, são frutos da produção humana, da escolha do que, como e onde construir, e não apenas um dado técnico absoluto, pois, como nos lembra Milton Santos, a técnica requer a política e vice-versa. Portanto, a opção de que objeto construir no âmbito territorial é coadunado com um desígnio de futuro, ou seja, de um projeto. Este dentro dos preceitos democráticos deverá ser uma escolha coletiva.

\section{Referências bibliográficas}

ABLAS, Luiz. Os "Estudos dos Eixos" como instrumento de planejamento regional. In: GONÇALVES, M. F.; BRANDÃO, C. A.; GALVÃO, A. C. F. (orgs). Regiões e Cidades, Cidades nas Regiões: o desafio urbano-regional. São Paulo: Editora UNESP: ANPUR, 2003.

CASTILlO, Ricardo; FREDERICO, Samuel. Dinâmica Regional e Globalização: espaços competitivos agrícolas no território brasileiro. Mercator, Fortaleza, v. 9, n. 18, jan./abr., 2010, p.17-26.

CNI. Confederação Nacional da Indústria. Sumário Executivo do Projeto Nordeste Competitivo. Brasília: CNI, 2012.

CNT. Confederação Nacional do Transporte. Plano CNT de Transporte e Logística 2011. Brasília: CNT, 2011.

Solução. Brasília: CNT, 2012.

CORRÊA, Roberto Lobato. Os Centros de Gestão do Território: uma nota. Revista Território, Rio de Janeiro, 1(1), p.23-30, 1996.

DUPAS, Gilberto. O mito do progresso; ou o progresso como ideologia. São Paulo: Editora Unesp, 2006.

HARVEY, David. O Enigma do Capital: e as crises do capitalismo. São Paulo: Boitempo, 2011.

. Os limites do capital. São Paulo: Boitempo, 2013.

MATUS, Carlos. O método PES. São Paulo: FUNDAP, 1996.

MÉSZÁROS, István. Estruturas sociais e formas de consciência: a determinação social do método. São Paulo: Boitempo, 2009.

PEDRÃO, Fernando. Tendências históricas e vontade política na formação espacial do Brasil. In: GONÇALVES, M. F.; BRANDÃO, C. A.; GALVÃO, A. C. F. (orgs). Regiões e Cidades, Cidades nas Regiões: o desafio urbano-regional. São Paulo: Editora UNESP: ANPUR, 2003. 
RIBEIRO, Ana Clara Torres. Pequena Reflexão Sobre Categorias da Teoria Crítica do Espaço: território usado, território praticado. In: Sousa, Maria Adélia de; et al. (org.). Território Brasileiro: usos e abusos. Campinas/SP: Edições Territorial, 2003.

SANTOS, Milton. Economia Espacial: Críticas e Alternativas. 2. ed., $2^{a}$ reimpr., São Paulo: Edusp, 2011 [1979].

- Metamorfose do Espaço Habitado: fundamentos teóricos e metodológicos da geografia. 6. ed., 1. reimpr., São Paulo: Edusp, 2012 [1988].

. O retorno do território. In: SANTOS, M.; SOUZA, M. A. de; SILVEIRA, M. L. (orgs.). Território: globalização e fragmentação. São Paulo: HUCITEC, 1994.

. A Natureza do Espaço: Técnica e Tempo. Razão e Emoção. 4. ed. São Paulo: Edusp, 2008 [1996].

. Por uma outra globalização: do pensamento único à consciência universal. 17. ed. Rio de Janeiro: Record, 2008 [2000].

O papel ativo da geografia: um manifesto. Revista Território, Rio de Janeiro, ano V, no 9, pp. 103-109, jul./dez., 2000.

; SILVEIRA, Maria Laura. O Brasil: território e sociedade no início do século XXI. 15ª ed., Rio de Janeiro: Record, 2011 [2001].

VAINER, Carlos. Planejamento Territorial e Projeto Nacional: os desafios da fragmentação. Revista Brasileira de Estudos Urbanos e Regionais, v. 9, n. 1, Maio, 2007, p.9-23.

\footnotetext{
Maxsuel de Moura Macedo

Mestre pelo Programa de Pós-Graduação e Pesquisa em Geografia da Universidade Federal do Rio Grande do Norte. Atua em pesquisas sobre Planejamento Territorial, Logística e Teoria da Geografia.

UFRN, CCHLA - Departamento de Geografia - Programa de Pós-Graduação em Geografia. Campus Universitário, s/n, Lagoa Nova - Natal (RN). Cep: 59078-970.

E-mail: maxsuelmmacedo@gmail.com
} 